\title{
LEI MAQUILA: IMPACTOS NO DESENVOLVIMENTO ECONÔMICO DO PARAGUAI DE 2003 A 2018
}

Maquila law: impacts in the economic development of Paraguay from 2003 to 2018

Francielly da Fonseca Costa

Mirian Beatriz Schneider

Flavio Braga de Almeida Gabriel

Gilson Batista de Oliveira 


\title{
LEI DE MAQUILA: IMPACTOS NO DESENVOLVIMENTO ECONÔMICO DO PARAGUAI DE 2003 A 2018
}

Maquila law: impacts in the economic development of Paraguay from 2003 to 2018

\author{
Francielly da Fonseca Costa \\ Mirian Beatriz Schneider \\ Flavio Braga de Almeida Gabriel \\ Gilson Batista de Oliveira
}

\begin{abstract}
Resumo: O presente trabalho teve como objetivo geral analisar os impactos da Lei de Maquila para o desenvolvimento econômico do Paraguai entre 2003 e 2018. Para isso, se propôs a estudar e mensurar dados referentes à Lei de Maquila do Paraguai, e a verificar a relação entre exportação e investimento externo direto nesse país, após a implantação desta lei, utilizando-se do método econométrico de modelo VAR para séries temporais. O que se constatou foi que o impacto que a Lei de Maquila proporcionou ao país no período estudado foi pouco relevante para a economia na sua totalidade, mas para o setor secundário foi de importante atuação para o seu crescimento e diversificação.
\end{abstract}

Palavras-Chaves: Lei de Maquila; Exportação; Investimento Estrangeiro Direto; Mínimos Quadrados Ordinários.

\begin{abstract}
The main objective of this study was to analyze the impact of the Maquila Law on the economic development of Paraguay between 2003 and 2018. Thus, it proposed to study and measure data related to the Paraguayan Maquila Law, the relationship between export and foreign direct investment in that country, after the implementation of this law, using the econometric method of time series VAR. What was found was that the impact that the Maquila Law provided to the country during the period studied was not very relevant for the economy as a whole, but for the secondary sector it was an important activity for its growth and diversification.
\end{abstract}

Key-words: Maquila Law; Export; Foreign Direct Investment; Ordinary Least Squares.

Resumen: El presente trabajo tuvo como objetivo general analizar los impactos de la Ley de Maquila para el desarrollo económico de Paraguay entre 2003 y 2018. Para este propósito, se propuso estudiar y medir datos referentes a la Ley de Maquila paraguaya, y verificar la relación entre las exportaciones e inversión extranjera directa en ese país, después de la implementación de esta ley, utilizando el método econométrico de VAR para series temporales. Lo que se encontró fue que el impacto que la Ley de Maquila tuvo en el país en el período estudiado fue de poca relevancia para la economía en general, pero para el sector secundario, fue importante para su crecimiento y diversificación.

Palabras clave: Ley de maquila; Exportación; Inversión extranjera directa; Mínimos cuadrados ordinarios. 
IGepec, Toledo, v. 24, n.1, p. 162-179, jan./jun. 2020. 


\section{INTRODUÇÃO}

As crises levam os governos a pensarem em estratégias econômicas de crescimento para seu país. Nesse sentido, fatores históricos e políticos do Paraguai, influenciaram desequilíbrios econômicos naquele país, como sua trajetória de governo autoritário e ditatorial na maior parte da segunda metade do século XX e problemas diplomáticos causados por seu alto índice de prática de atividades ilícitas (ESPOSITO NETO, 2011).

Outro entrave perceptível, é a alta relevância que o preço internacional da soja, um dos seus importantes itens de exportação, tem para o crescimento econômico desse país. Dessa maneira, entre 2000 e 2018 o PIB paraguaio sofreu picos de taxa de crescimento de mais de 10\% ao ano em 2010 e 2013, porém, em 2000, 2001, 2002, 2009 e 2012, teve taxas de crescimento negativas, justamente acompanhando o as oscilações do preço dessa commodity agrícola (BORDA, 2007; WORLD BANK, 2015).

Uma estratégia implantada pelo governo paraguaio com o intuito de assegurar aumento do emprego, do crescimento econômico e principalmente da exportação e atração de investimento estrangeiro na indústria, foi a criação da Lei no ${ }^{0} 1064$ de 1997 , chamada de Lei de Maquila.

As diretrizes dessa lei possibilitam que empresas estrangeiras instalem filiais neste país direcionadas à exportação e para isso recebem isenções fiscais devendo pagar apenas o imposto de 1\% sobre o total das exportações. Além disso, não há, para essas empresas, impostos à importação de matérias primas e equipamentos, mas as maquiladoras são obrigadas a exportar 90\% da sua produção (CEMAP, 2016, PARAGUAI, 1997). Diante dessas vantagens e incentivos, em 2015, das 102 empresas no Programa de Maquila, 80\% delas possuíam investimento brasileiro (MENDONÇA, 2015, TURCO, 2016).

Isto posto, esse trabalho, teve como objetivos expor a evolução do setor maquilador no Paraguai desde a sua criação em 1997 até 2018, e analisar quantitativamente a sua política de promoção à exportação utilizando do Método de Séries Temporais com Modelo de Vetor Auto-Regressivo (VAR) para verificar a relação entre as variáveis Exportação e Investimento Externo Direto do Paraguai, e testar a hipótese de que "os investimentos estrangeiros diretos (IED) influenciam de forma positiva as exportações (EXP) do Paraguai", a fim de responder à questão chave deste trabalho: Quais os impactos da Lei de Maquila para o desenvolvimento econômico do Paraguai de 2003 a 2018?

\section{A LEI DE MAQUILA DO PARAGUAI}

Maquila é uma palavra oriunda do árabe makīlah e significa coisa medida. $\mathrm{Na}$ língua espanhola ganhou o conceito de porção de grão, farinha ou azeite que corresponde ao moleiro pela fresagem (LEXICOON, 2017). Esse termo também tem sido utilizado para designar as indústrias que fabricam parte da produção para uma empresa de matriz estrangeira cujo o objetivo é a exportação, e tem o México como pioneiro na adoção dessa terminologia para a sua Industria Maquiladora iniciada no século XX (VILLALPANDO, 2004).

Em 1965 surgia o Programa Indústria Maquiladora de Exportação no México, uma indústria que visava reduzir o desemprego na região fronteiriça com os Estados Unidos e desenvolver a industrialização local. Suas diretrizes permitiam a importação de maquinários, equipamentos e componentes, livre de impostos, porém os produtos transformados nessa indústria necessariamente deveriam ser reexportados, e também essas poderiam receber $100 \%$ de capital estrangeiro, diferente das outras modalidades 
de empresas mexicanas (TORRES; BRAVO, 1999). A indústria maquiladora representa ainda hoje uma importante fonte de divisas e emprego para o México, tendo, em 2015, cerca de 5008 maquiladoras atuando na fabricação de autopeças, eletrônica e têxtil, tendo 2.245.438 pessoas trabalhando nesse programa (MACIEL, 2017).

Com base neste modelo, a Lei da Indústria Maquiladora de Exportação do Paraguai, mais comumente chamada de Lei de Maquila, ou Lei no 1064 de 1997, foi criada com o intuito de estimular a sua indústria e exportação por meio de investimento externo direto, além de gerar emprego e renda. A lei trata de manter um regime tributário e obrigações diferenciadas para a produção das maquiladoras, essas que são então classificadas em cinco modalidades: maquila, maquila por capacidade ociosa, submaquila, maquila de serviço intangível e maquila com programa albergue ou shelter (FIEMS, 2015).

O foco da lei é predominantemente a exportação. Porém, parte da produção pode ser direcionada ao mercado interno paraguaio, $10 \%$ do volume exportado no ano anterior, devendo obter a autorização do Consejo Nacional de la Industria Maquiladora de Exportación (CNIME), manter a mesmo controle e qualidade das mercadorias destinadas à exportação e arcar com todos os impostos referentes à nacionalização desses produtos (PARAGUAI, 1997).

Como as maquiladoras são filiais ou contratadas de empresas estrangeiras, o principal incentivo previsto na lei para atração do investimento externo é de ordem fiscal, implica em um imposto único de $1 \%$ sobre o valor agregado em território nacional, isentas de outros tributos de departamentos nacionais ou municipais bem como tributos sobre importações de bens de capital e insumos utilizados na produção em território paraguaio.

Outros fatores também são levados em consideração como incentivos ao investimento estrangeiro, principalmente no Brasil que os divulga por meio de organizações do setor industrial como Confederação Nacional da Indústria (CNI) e do Serviço Brasileiro de Apoio às Micro e Pequenas Empresas (SEBRAE). Esses fatores são relacionados à situação econômica e social do Paraguai, a estabilidade econômica, do crescimento do PIB que, desde 2010, é alto e positivo, com exceção apenas no ano de 2012, da taxa de inflação que desde 2011 não supera 4,9\% ao ano, o custo de mãode-obra (fragilidade dos sindicatos), e energia elétrica relativamente mais barata (FIEMS, 2015, SEBRAE, 2016; BANCO CENTRAL DO PARAGUAI, 2020).

A principal obrigação das maquiladoras é exportar sua produção conforme os termos do acordo, porém em detrimento da participação no Mercosul, devem seguir a regra de origem do valor agregado, que atualmente consiste em $40 \%$ oriundo dos países membros e 60\% de países de fora do Mercosul, o que significa que pelo menos $40 \%$ do valor dos insumos totais, incluindo-se bens necessários à produção e os serviços contratados, devem ser oriundos dos países membros do Mercosul.

Na Figura 1, se expressa resumidamente as relações e processos que ocorrem dentro do Regime de Maquila. 
Figura 1 - Fluxo da Industria Maquiladora de Exportação do Paraguai Fonte: MACIEL, 2017, p. 71.

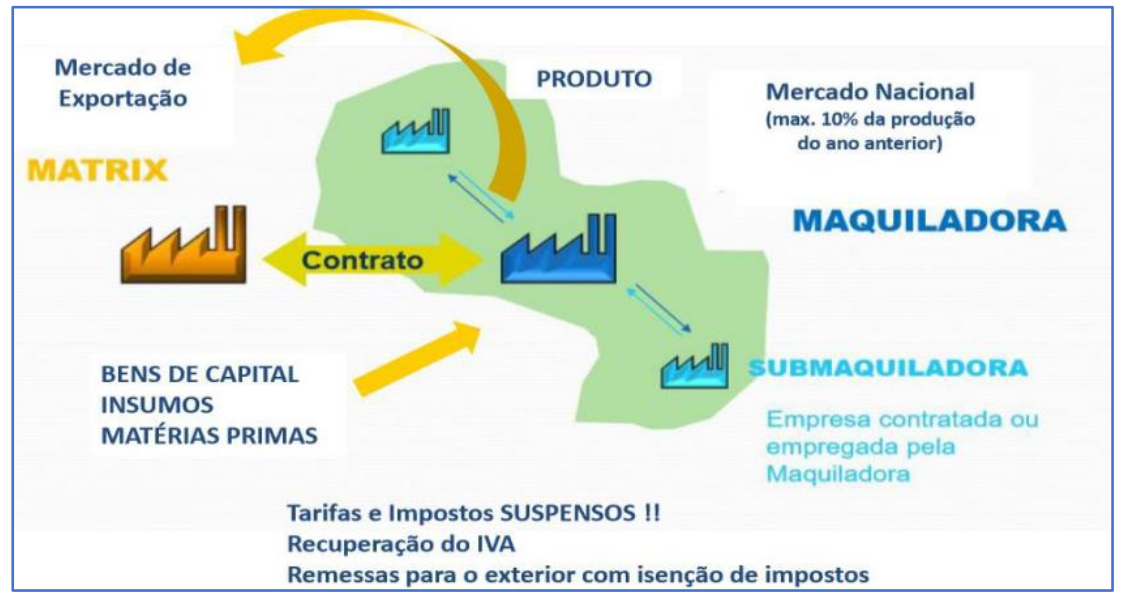

A empresa maquiladora em território paraguaio pode receber bens de capital, insumos e matérias-primas da sua matriz sem custos e ainda pode contratar uma empresa paraguaia, a determinada submaquiladora, com capacidade ociosa para suprir mão-de-obra ou fornecer produtos e serviços.

No Quadro 1 se expõe, resumidamente, os principais fatores econômicos, sociais, fiscais e legais utilizados para incentivar o investimento externo direto e consequentemente melhorar as exportações no programa de indústria maquiladora do Paraguai.

Quadro 1 - Principais aspectos do Paraguai e da Lei de Maquila utilizadas para atrair investimento estrangeiro.

\begin{tabular}{|c|c|}
\hline & $\begin{array}{l}\text { O único tributo destinado a empresa maquiladora é de } 1 \% \text { sobre o valor agregado total de sua } \\
\text { produção. } \\
\text { A produção deve ser exportada em prazos estipulados pelo contrato previamente. }\end{array}$ \\
\hline & Os insumos e matérias-primas dos países do Mercosul têm preferência dentro desse sistema. \\
\hline $\begin{array}{l}\text { Fatores } \\
\text { econômicos }\end{array}$ & $\begin{array}{l}\text { O custo com energia é relativamente menor que nos países vizinhos. } \\
\text { Satisfatória estabilidade econômica. } \\
\text { As importações de insumos e matérias-primas vindas da matriz não são taxadas. }\end{array}$ \\
\hline $\begin{array}{l}\text { Fatores } \\
\text { sociais }\end{array}$ & $\begin{array}{l}\text { O custo da mão de obra relativamente menor que para os países vizinhos. } \\
\text { As articulações sindicais são relativamente mais frágeis que nos países vizinhos. }\end{array}$ \\
\hline
\end{tabular}

Fonte: Elaborado pela Pesquisa (2020), com base em FIEMS (2015).

Devido aos incentivos citados, no ano de 2016 existiam 120 empresas maquiladoras, o que pode ser considerado um número pequeno de empresas instaladas em 2 décadas. Porém, o investimento é consideravelmente alto, pois, "em média, um projeto nesse regime corresponde a um investimento de 2 milhões a 3 milhões de dólares, com mão de obra de 100 empregados por unidade" (TURCO, 2016, p. 47).

A maioria das maquiladoras estão implantadas na Região do Alto Paraná $(47,27 \%)$ e Região do Departamento Central (42,72\%). A primeira região tem como capital a Ciudad del Este, enquanto que a segunda região tem como capital o município de Assunción. No mapa da Figura 2, essa observação fica bem clara. É clara a preferência por regiões de fronteira com o Brasil e Argentina e com maior densidade 
populacional, o que é compreensível quando se observa de onde vêm os investimentos, pois a maioria absoluta são capitais de brasileiros (82), seguidos por uruguaios (15), estadunidenses (6) e argentinos (5), nessa ordem. China, Itália e Panamá contam com 2 maquiladoras cada, e Espanha, Hong Kong, Ilhas Virgens, Inglaterra, Líbano e Luxemburgo com 1 cada.

Figura 2 - Mapa de alocação das maquilados no Paraguai em 2016

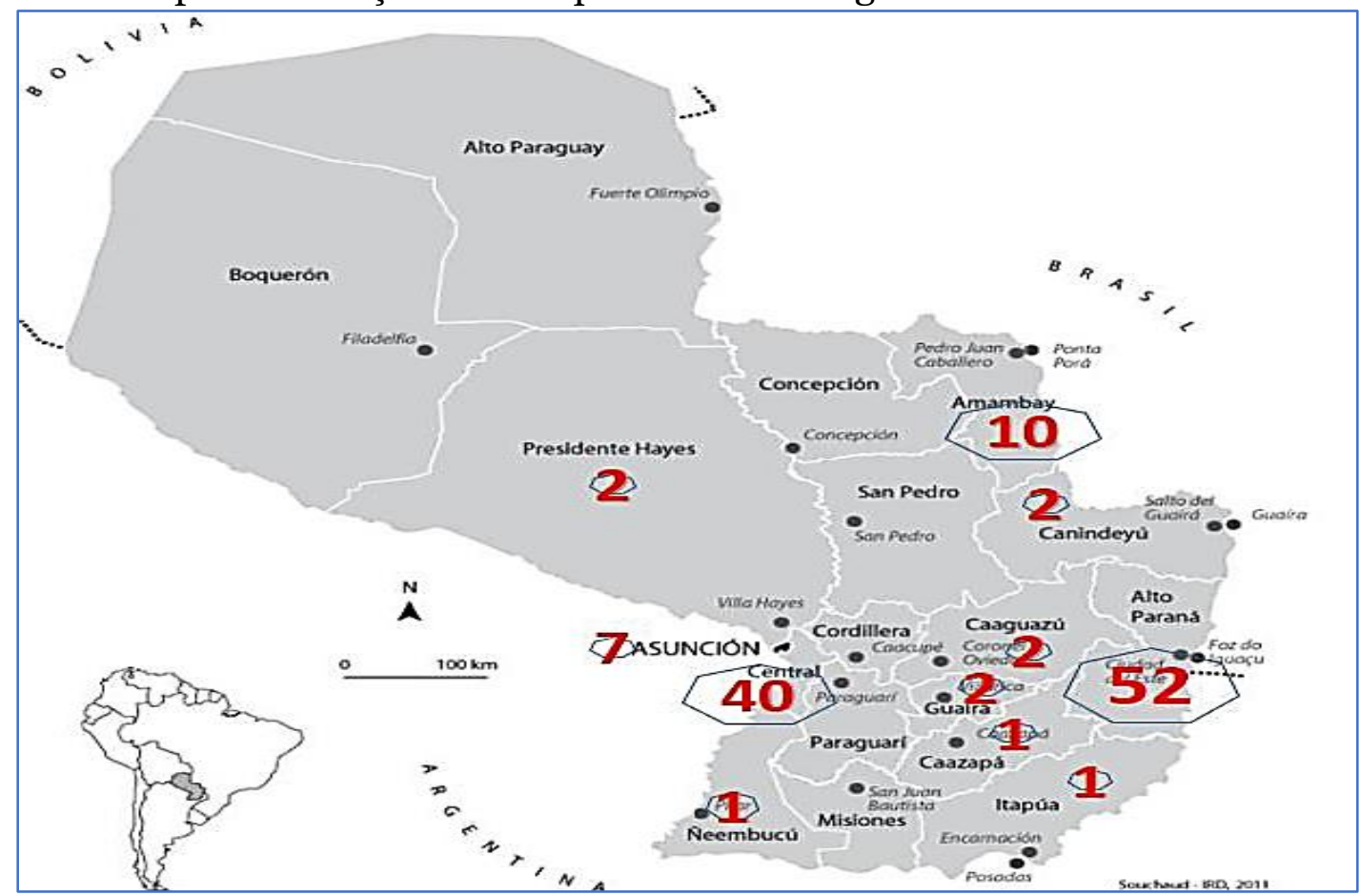

Fonte: MACIEL, 2017, p. 73.

Das 120 maquiladoras, 68,33\% têm matriz no Brasil, e baseado em informações obtidas com o CNIME, “77\% das exportações provenientes das maquilas são destinadas para o Mercosul, sendo que a maior parte para o Brasil e Argentina. O restante das exportações (33\%) é dirigido para a Tailândia, Indonésia, China, França e Vietnã" (SILVEIRA, 2016, p. 181).

As exportações médias das maquiladoras de 2001 a 2005 foram de 9 milhões de dólares, e, a partir de 2010, tiveram um grande crescimento, passando de 102 milhões de dólares, mantendo a tendência de alta desde então, alcançando em torno de US\$ 250 milhões em 2014 e U\$ 285 milhões em 2015, conforme se apresenta no Gráfico 1.

Gráfico 1 - Exportações das Maquiladoras de 2001 a 2015, em dólares.

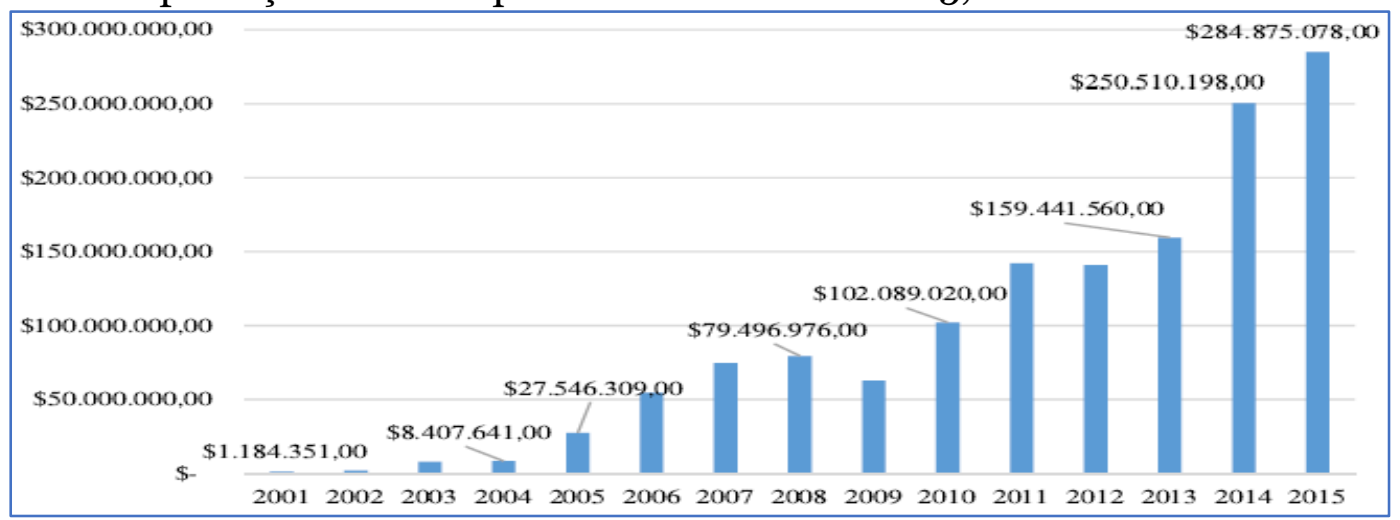

Fonte: SILVEIRA, 2016, p. 183, com base em dados do CNIME. 
As exportações de maquila representaram, em 2004, cerca de 6\% das exportações de produtos manufaturados de origem industrial, mas essa participação foi aumentando, passando para 26\% em 2010 e alcançando 38\% em 2015. Entende-se com isso que a criação da indústria maquiladora de exportação elevou o dinamismo do setor secundário do Paraguai, expandindo a participação desse setor nas exportações totais do país.

A indústria tem atuado especialmente nos ramos de fabricação de produtos têxteis, plásticos e suas manufaturas e autopeças, tendo mais de 60\% das maquiladoras operando nessas três atividades. Porém, algumas outras atividades também têm se destacado, como é o caso do ramo de metalurgia e suas manufaturas (7\%), serviços (6\%), calçados (3\%), tintas e madeiras (3\%).

Pode-se verificar a quantidade de empresas maquiladoras que operam em cada ramo de atividade no Gráfico 2.

Gráfico 2 - Alocação de maquiladoras por ramos de atividades em 2017.

Fonte: MACIEL, 2017.

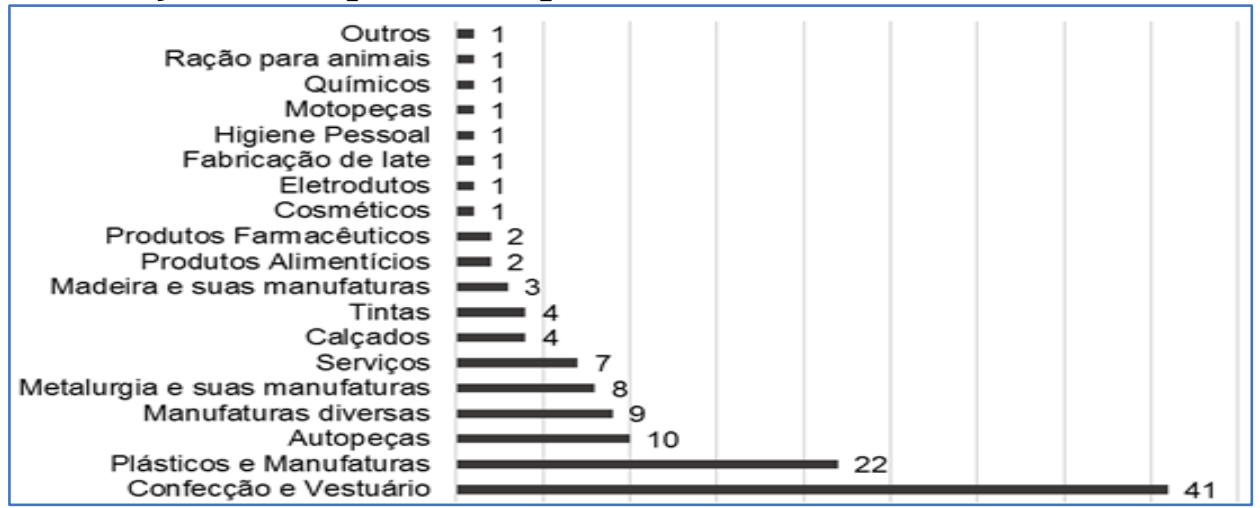

Outro aspecto importante da contribuição da indústria maquiladora para o dinamismo da economia do Paraguai foi que ela tem criado, em média, 888 novos postos de emprego por ano desde 2001, conforme Gráfico 3.

Gráfico 3 - Emprego gerado por ano no Regime de Maquila de 2001 a 2016.

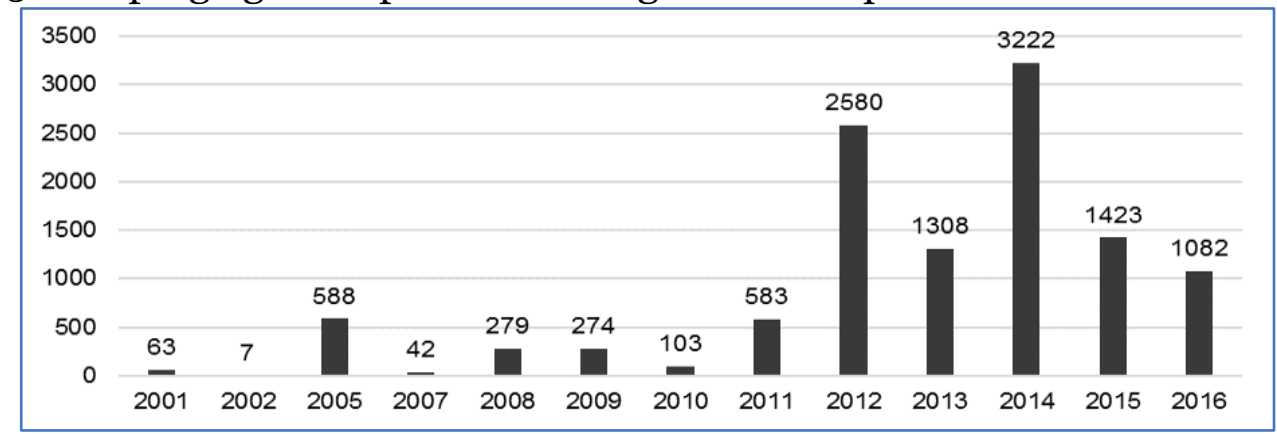

Fonte: MACIEL, 2017.

A geração de empregos foi bem expressiva em 2012 e em 2014, contribuindo com a criação de 2580 e 3222 postos de emprego respectivamente. Observando o

1 Ressalta-se aqui a dificuldade em se obter quaisquer dados sobre as maquiladoras do Paraguai. As entidades responsáveis não disponibilizam uma plataforma transparente com dados de interesses de pesquisadores e 0 contato com essas entidades é restrito e confuso. No caso da pesquisa que originou esse artigo, nas situações em que o contato foi alcançado, a resposta obtida foi negativa quanto à disponibilização de dados tanto antigos quando recentes. Ver os apêndices de Costa (2018). 
montante total acumulado no período, tem-se que, em 16 anos foram criados cerca de 11554 empregos no Paraguai.

Assim, baseado na dinâmica dos dados referentes às maquiladoras do Paraguai, pode-se afirmar que a Lei de Maquila teve uma evolução crescente desde 2001, que talvez dentro da representação da totalidade da economia paraguaia não tenha sido muito expressiva, mas dentro do setor secundário já demonstrou grande representatividade nas exportações e geração de postos de emprego.

\section{METODOLOGIA}

Essa pesquisa buscou analisar os impactos da Lei 1064/97 do Paraguai, Lei de Maquila, sobre a exportação do Paraguai. Assim a hipótese dessa pesquisa é: os Investimentos estrangeiros diretos (IED) influenciam de forma positiva as exportações (EXP) do Paraguai. Para se testar essa hipótese, utilizou-se o modelo econométrico Vetor Auto-Regressivo (VAR) para séries temporais. Foram utilizados dados secundários do Banco Central do Paraguai: as exportações e o investimento estrangeiro direto trimestrais no Paraguai, do primeiro trimestre de 2003 ao quarto trimestre de 2018 em US\$ atualizados.

\subsection{MODELO VAR - VETOR AUTO-REGRESSIVO}

A premissa que levou a formação dessa hipótese leva em consideração a Política de Promoção à Exportação que é praticada no Paraguai por meio da Indústria Maquiladora de Exportação. Como a Indústria Maquiladora de Exportação é financiada com IED, existe uma política governamental de incentivos para atração de IED que englobam baixos custos de mão-de-obra, de recursos naturais e energia elétrica, além de isenções fiscais. No entanto, é uma obrigação das empresas que participam do Regime de Maquila, exportar a sua produção, o que demonstra que a exportação é o objetivo central da Política de Promoção à Exportação, e o IED é que possibilita o aumento e diversificação das exportações.

Os modelos VAR são muito utilizados para descrever as características estocásticas de séries econômicas e para realizar previsões. No modelo VAR tem-se que erro das equações sofre o comportamento de um ruído branco $\varepsilon t ~ \sim R B(0,1)$ e são nãocorrelacionados, porém as variáveis consideradas endógenas devem ser estacionárias, o que pode ser verificado se aplicando testes de raiz unitária, como Dickey-Fuller (DF), Dickey-Fuller aumentado (ADF), Phillips-Perron (PP) e Kwiatkowski, Phillips, Shimidt e Shin (KPSS) (DA SILVA JUNIOR; MENEZES; FERNANDEZ, 2011; PONTES, 2018).

No caso de variáveis não estacionárias, deve-se verificar a ordem de integração e se estas forem integradas de mesma ordem, e depois fazer um teste de cointegração, pois, quando se diferencia as variáveis, omite-se a possibilidade da existência das relações de longo prazo. Se há cointegração, uma especificação mais adequada é um VAR nas diferenças aumentado por termos de correção de erros, o que constitui um modelo de correção de erro denominado Vetor de Correção de Erro (VEC) (ENDERS, 1995).

Pode-se expressar um modelo VAR de ordem $p$ por um vetor com $n$ variáveis endógenas, $X_{t}$, que estão conectadas entre si por uma matriz A, assim tem-se que:

$$
A X_{t}=\beta_{0}+\sum_{i=1}^{p} \beta_{i} X_{t-i}+\varepsilon_{t}
$$

No qual: $A$ é uma matriz ( $n \times n)$ que define as restrições contemporâneas entre as variáveis que constituem o vetor $X_{t} ; X_{t}$ é um vetor $(n x 1)$ de variáveis econômicas 
de interesse no instante $t ; \beta_{0}$ é um vetor de constantes ( $\left.n \times 1\right) ; \beta_{i}$ é uma matriz ( $\left.n \times n\right)$ de coeficientes, com $i=o, \ldots, p$; e $\varepsilon_{t}$, um vetor $(n \times 1)$ de perturbações aleatórias não correlacionadas entre si contemporânea ou temporalmente, isto é, $\varepsilon_{t} \sim$ i.i.d.(o; $\left.I_{n}\right)$.

E para a escolha da ordem da defasagem $p$ do modelo VAR deve-se obter a menor estimação do critério de informação de Akaike (AIC), Schwarz (SC) e HannanQuim (HQ) conforme as expressões (2) (3) e (4). Como o modelo leva em consideração o a soma do quadrado dos resíduos, o número de observações e de estimadores do parâmetro, quanto menores os valores desses critérios, melhor será o modelo bem como menor será o número de defasagens (PONTES, 2018).

$$
\begin{gathered}
\left(p^{\wedge}\right)=\ln \left|\sum(p)\right|+2 T \text { pn } 2 \\
\left(p^{\wedge}\right)=\ln \left|\sum(p)\right|+\ln T \text { T pn } 2 \\
\left(p^{\hat{n}}\right)=\ln \left|\sum(p)\right|+\ln (\ln T) T 2 p n 2
\end{gathered}
$$

Assim, tem-se a equação representativa do modelo em estudo:

$$
\text { Pyexp }=\beta_{0}+\beta_{1}(\text { Pyflu })+\varepsilon_{t}
$$

Em que:

Pyexp $p_{i}=$ Exportação do Paraguai, variável dependente; $P y f l u_{i}=$ Fluxo de Investimento Externo Direto no Paraguai, variável independente; dados trimestrais de 2003 a 2018.

Para a realização dos procedimentos estatísticos, foi utilizado o software EViews versão 10.

As complexas interações entre as variáveis do Modelo VAR (p) demandam de uma análise aprofundada dos resultados, e para isto são comumente utilizados os testes: (1) causalidade de Granger, (2) funções de impulso resposta e (3) análise de decomposição da variância dos resíduos, afim de proporcionar uma maior robustez para as considerações advindas dos resultados (ZIVOT e WANG, 2007).

Por fim, deve-se ressaltar que tanto as Exportações, quanto o Fluxo de Investimento Estrangeiro Direto do Paraguai recebem influência de inúmeros fatores que não são abordados neste estudo, portanto, o resultado somente faz sentido se se considerar que todas os outros fatores que na realidade influenciam no desempenho das variáveis em análise se mantêm constantes.

\section{RESULTADOS E DISCUSSÕES}

O primeiro passo adotado foi a verificação de estacionaridade das variáveis Pyexp e Pyflu, ou seja, se são séries que se desenvolvem no tempo aleatoriamente ao redor de uma média constante, refletindo alguma forma de equilíbrio estável. Pode-se observar na Figura 3 uma aparente estacionaridade. 
Figura 3 - Distribuição das séries de Exportação e Fluxo de Investimento Estrangeiro Direto do Paraguai em trimestres de 2003 a 2018

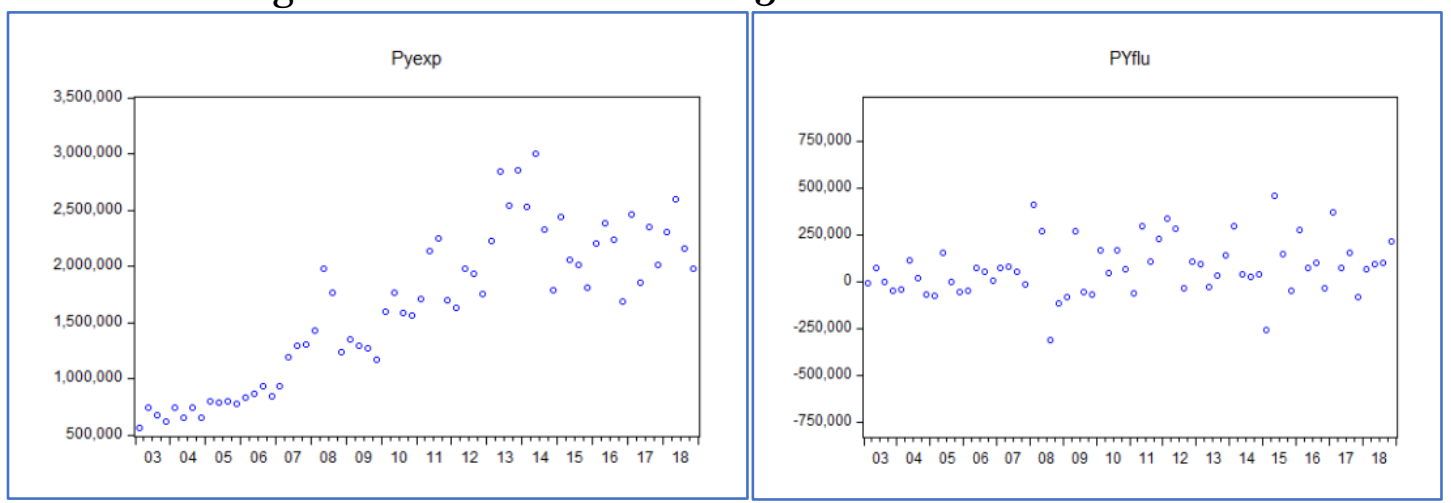

Fonte: Elaborado pela pesquisa (2020) a partir de dados do Banco Central do Paraguai.

Utilizou-se do teste de Dickey-Fuller Aumentado para confirmar a presença de raiz unitária. Encontrou-se para Pyexp o t estatístico de -4,021308 e para Pyflu 8,506346 , os quais sendo em módulo maiores que o valor crítico de $-3,720600$, demonstram que, em level, com a significância de $1 \%$ as duas variáveis contêm raiz unitária, portanto são estacionárias.

No segundo passo, procurou-se identificar a defasagem do Modelo VAR a ser rodado, para isso utilizou-se da opção no programa Eviews na qual se calcula todos os critérios de seleção de ordem de defasagem, conforme Tabela 1.

Tabela 1 - Critérios de seleção de ordem de defasagem para VAR

\begin{tabular}{ccccccc}
\hline \hline Lag & LogL & LR & FPE & AIC & SC & HQ \\
\hline \hline 0 & -1627.196 & NA & $8.58 e+21$ & 56.17919 & 56.25024 & 56.20686 \\
1 & -1587.754 & $74.80502^{*}$ & $2.53 e+21$ & 54.95703 & $55.17018^{*}$ & $55.04005^{\star}$ \\
2 & -1583.238 & 8.252763 & $2.48 \mathrm{e}+21^{*}$ & $54.93925^{*}$ & 55.29450 & 55.07762 \\
3 & -1581.951 & 2.262912 & $2.73 e+21$ & 55.03281 & 55.53016 & 55.22653 \\
4 & -1576.782 & 8.734348 & $2.63 e+21$ & 54.99249 & 55.63193 & 55.24156 \\
5 & -1574.142 & 4.277984 & $2.77 \mathrm{e}+21$ & 55.03940 & 55.82094 & 55.34382 \\
6 & -1573.320 & 1.275490 & $3.11 \mathrm{e}+21$ & 55.14898 & 56.07263 & 55.50876 \\
\hline \hline
\end{tabular}

Fonte: Resultados da Pesquisa, 2020.

Assim, utilizando do critério da parcimônia, quando menos defasagens melhor para o ajuste do modelo, optou-se por 1 defasagem, escolha baseada nos resultados do critério de informação de Schwarz e do critério de informação de Hannan-Quinn.

No terceiro passo foi estimado o Modelo VAR com uma defasagem, os resultados podem ser observados na saída do Eviews na Figura 4. 
Figura 4 - Estimação do Modelo de Vetor Auto-Regressivo (VAR)

\begin{tabular}{|c|c|c|c|c|c|}
\hline \multicolumn{3}{|c|}{$\begin{array}{l}\text { Vector Autoregression Estimates } \\
\text { Date: 02/14/20 Time: } 15: 12 \\
\text { Sample (adjusted): } 2003 \mathrm{Q} 2 \text { 2018Q4 } \\
\text { Included observations: } 63 \text { after adjustments } \\
\text { Standard errors in ( ) \& t-statistics in [ ] } \\
\end{array}$} & \multirow{3}{*}{\begin{tabular}{|l} 
R-squared \\
Adj. R-squared \\
Sum sq. resids \\
S.E. equation \\
F-statistic \\
Log likelihood \\
Akaike AIC \\
Schwarz SC \\
Mean dependent \\
S.D. dependent
\end{tabular}} & \multirow{3}{*}{$\begin{array}{r}0.782029 \\
0.774763 \\
5.85 \mathrm{E}+12 \\
312163.3 \\
107.6331 \\
-884.8870 \\
28.18689 \\
28.28894 \\
1648726 . \\
657752.3\end{array}$} & \multirow{3}{*}{$\begin{array}{r}0.042128 \\
0.010199 \\
1.29 \mathrm{E}+12 \\
146611.9 \\
1.319437 \\
-837.2755 \\
26.67541 \\
26.77747 \\
77318.93 \\
147365.3\end{array}$} \\
\hline & PYEXP & PYFLU & & & \\
\hline $\operatorname{PYEXP}(-1)$ & $\begin{array}{c}0.847442 \\
(0.06123) \\
{[13.8407]}\end{array}$ & $\begin{array}{l}0.046397 \\
(0.02876) \\
{[1.61344]}\end{array}$ & & & \\
\hline PYFLU(-1) & $\begin{array}{c}0.309419 \\
(0.27988) \\
{[1.10555]}\end{array}$ & $\begin{array}{r}-0.079074 \\
(0.13145) \\
{[-0.60156]}\end{array}$ & \multirow{2}{*}{\multicolumn{2}{|c|}{$\begin{array}{l}\text { Determinant resid covariance (dof adj.) } \\
\text { Determinant resid covariance } \\
\text { Log likelihood } \\
\text { Akaike information criterion } \\
\text { Schwarz criterion } \\
\text { Number of coefficients }\end{array}$}} & $\begin{array}{r}2.01 \mathrm{E}+21 \\
1.82 \mathrm{E}+21 \\
-1720813\end{array}$ \\
\hline C & $\begin{array}{l}247803.6 \\
(104012 .) \\
{[2.38245]}\end{array}$ & $\begin{array}{r}7705.467 \\
(48850.7) \\
{[0.15773]}\end{array}$ & & & $\begin{array}{c}54.81946 \\
55.02357 \\
6\end{array}$ \\
\hline
\end{tabular}

Fonte: Resultados da Pesquisa, 2020.

Conforme os resultados do modelo Var, observa-se que teve um bom ajustamento, pois considera-se o $\mathrm{R}^{2}(0,782029)$ e o $\mathrm{R}^{2}$ ajustados $(0,774763)$ coeficientes de determinação altamente explicativos quando maiores de 0,7.

No entanto, os resultados dos parâmetros devem ser analisados com maior atenção, os valores entre colchetes são as estatísticas do teste $t$ de distribuição normal padrão, as quais devem ser confrontadas com o valor crítico de 1,96 para o teste bicaudal, que infere $5 \%$ de significância para se rejeitar a hipótese nula de que o valor gerado para o parâmetro é irrelevante para o modelo. Caso as estatísticas de $t$ sejam maiores que 1,96 se rejeita essa hipótese nula.

Dessa forma, as únicas influencias que foram consideradas relevantes no modelo, foram as influencias da exportação do Paraguai nela mesma [13,8407] e do intercepto $c$ nas exportações do Paraguai [2,38245].

Essa interpretação também resulta do Teste de Causalidade de Granger, Tabela 2, pois nas duas situações de influência, observou-se que a hipótese nula - não causa Granger - não foi refutada, pois a significância (prob.) foi maior do que 0,05.

Tabela 2 - Testes de Causalidade de Granger

\begin{tabular}{lcrc}
\hline \hline Null Hypothesis: & Obs & F-Statistic & Prob. \\
\hline \hline PYFLU does not Granger Cause PYEXP & \multirow{2}{*}{63} & 1.22224 & $\begin{array}{l}0.2733 \\
\text { PYEXP does not Granger Cause PYFLU }\end{array}$ \\
\hline \hline
\end{tabular}

Fonte: Resultados da Pesquisa, 2020.

Os gráficos das funções de impulso resposta demonstraram que as exportações reagem muito significativamente às suas próprias alterações, mas nos outros casos, as respostas são tímidas e rápidas (FIGURA 5). No entanto, apesar de tímida, é visível uma certa reação das exportações com relação as alterações nos fluxos de IED, um distúrbio que se normaliza depois do $4^{\circ}$ período. 
Figura 5 - Funções de impulso resposta para o modelo VAR

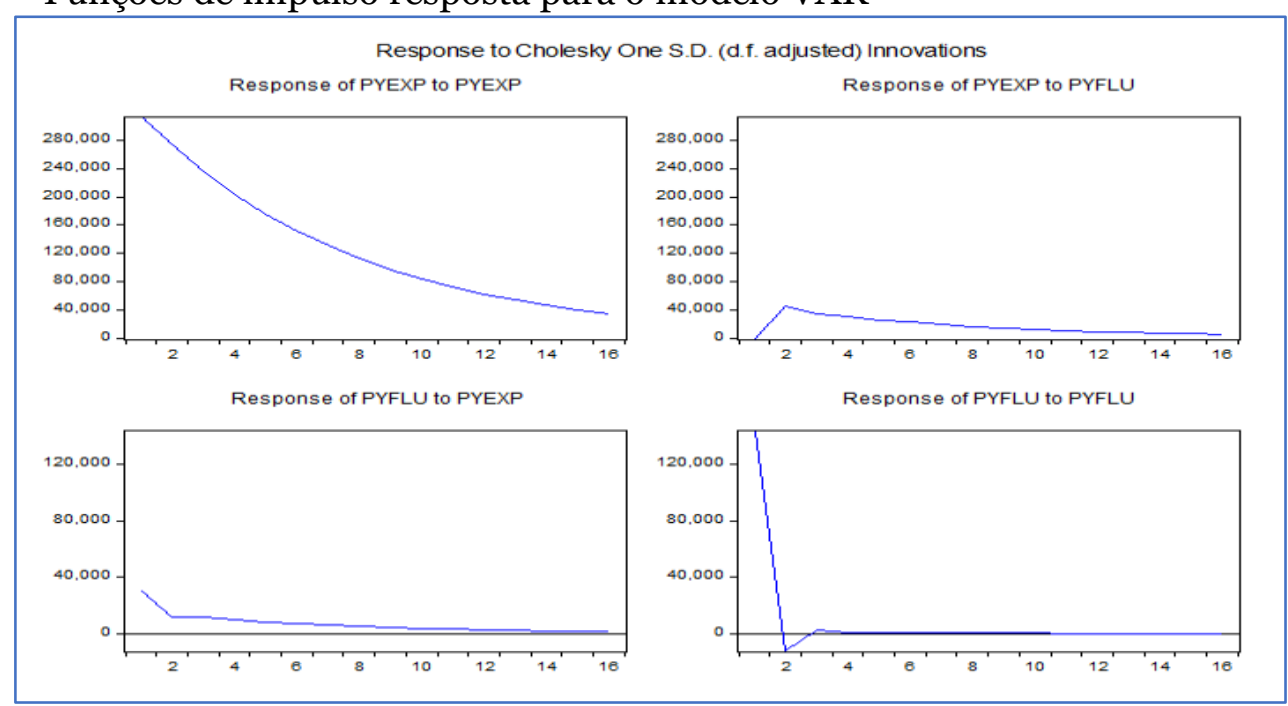

Fonte: Resultados da Pesquisa, 2020.

Por fim, analisando a decomposição da variância as duas variáveis têm muito pouco impacto uma na outra em termos percentuais. O Impacto de Pyexp em Pyflu sobe de $4 \%$ para $7 \%$ ao final de 16 anos, e no caso do impacto de Pyflu em Pyexp não passa de $1,6 \%$ em todo o período.

Tebela 3 - Decomposição da Variância de Pyflu e PyExp

\begin{tabular}{cccccccc}
\multicolumn{2}{l}{$\begin{array}{l}\text { Variance Decomposition of PYFLU: } \\
\text { Period }\end{array}$} & S.E. & PYEXP & PYFLU & Pariance Decomposition of PYEXP: \\
\hline \hline 1 & 146611.9 & 4.193671 & 95.80633 & 1 & 312163.3 & 100.0000 & 0.000000 \\
2 & 147548.1 & 4.814188 & 95.18581 & 2 & 417612.9 & 98.86948 & 1.130523 \\
3 & 148044.6 & 5.411610 & 94.58839 & 3 & 480798.6 & 98.64355 & 1.356452 \\
4 & 148388.9 & 5.841738 & 94.15826 & 4 & 522928.7 & 98.52795 & 1.472051 \\
5 & 148646.2 & 6.160045 & 93.83996 & 5 & 552197.8 & 98.46334 & 1.536660 \\
6 & 148837.2 & 6.395450 & 93.60455 & 6 & 573011.4 & 98.42325 & 1.576753 \\
7 & 148979.3 & 6.569867 & 93.43013 & 7 & 588023.4 & 98.39694 & 1.603062 \\
8 & 149084.9 & 6.699242 & 93.30076 & 8 & 598951.6 & 98.37902 & 1.620983 \\
9 & 149163.5 & 6.795289 & 93.20471 & 9 & 606957.0 & 98.36650 & 1.633501 \\
10 & 149221.9 & 6.866638 & 93.13336 & 10 & 612846.9 & 98.35760 & 1.642400 \\
11 & 149265.4 & 6.919666 & 93.08033 & 11 & 617193.9 & 98.35120 & 1.648805 \\
12 & 149297.7 & 6.959090 & 93.04091 & 12 & 620409.3 & 98.34654 & 1.653456 \\
13 & 149321.8 & 6.988409 & 93.01159 & 13 & 622791.5 & 98.34314 & 1.656856 \\
14 & 149339.7 & 7.010217 & 92.98978 & 14 & 624558.5 & 98.34065 & 1.659352 \\
15 & 149353.1 & 7.026439 & 92.97356 & 15 & 625870.3 & 98.33881 & 1.661192 \\
16 & 149363.0 & 7.038509 & 92.96149 & 16 & 626844.8 & 98.33745 & 1.662551 \\
\hline
\end{tabular}

Fonte: Resultados da Pesquisa, 2020.

Esses resultados evidenciam que a Hipótese apresentada nesse trabalho de que o Investimento Estrangeiro Direto influencia de maneira positiva nas Exportações do Paraguai, apesar de aparecer com sinal positivo na estimação do modelo VAR, não pode ser confirmação com um nível de confiança satisfatório, de modo que se rejeita essa hipótese.

Mas, esse resultado não deixa de ser compreensível, quando se observa a estrutura do IED e das Exportações no Paraguai conforme gráficos 4 e 5 . 
Gráfico 4 - Total de IED por setor produtivo no Paraguai de 2003 a 2016, em milhares de US\$.

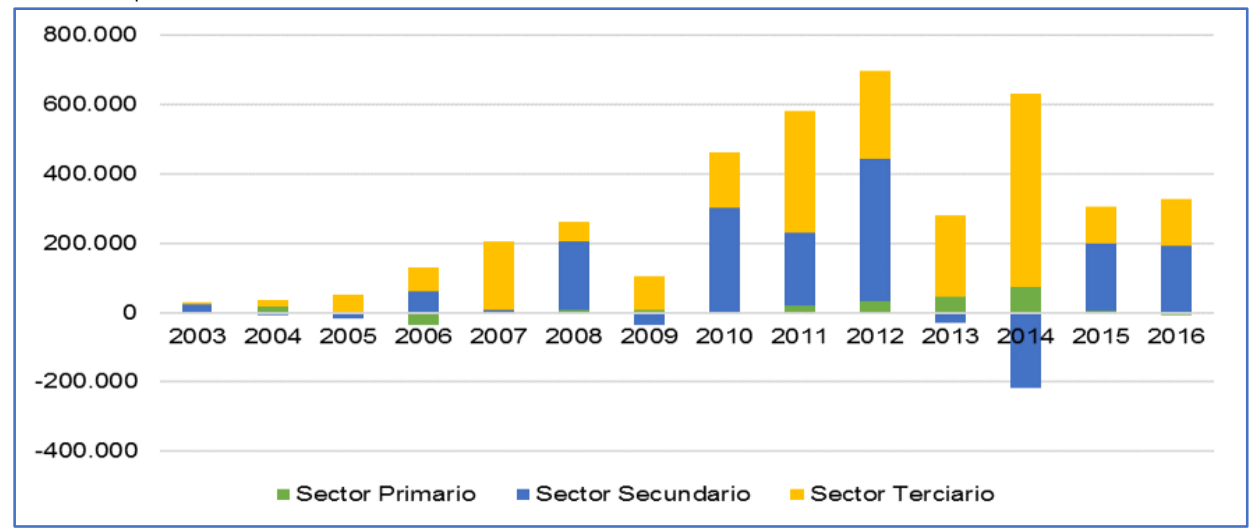

Fonte: BANCO CENTRAL DEL PARAGUAY, 2020.

No período analisado os investimentos estrangeiros diretos se mantiveram concentrados nos setores secundários e terciário na economia do Paraguai, com participação muito pequena nas atividades do setor primário, conforme o Gráfico 4.

Enquanto que a dinâmica das exportações, Gráfico 5, evidenciou o oposto, as maiores parcelas das exportações nesse período são de produtos do setor primário, e de energia hidrelétrica, enquanto que as exportações de bens do setor secundário, são bem pouco expressivas, porém são crescentes, o que pode ser considerado resultado da política de promoção a exportação por meio da Industria Maquiladora.

De certa forma, o resultado do modelo econométrico está de acordo com a realidade, pois, a maior parte do IED paraguaio está nas atividades industriais e serviços, que, por sua vez, são as atividades menos expressivas nas exportações desse país.

Gráfico 5 - Total das exportações por setor produtivo no Paraguai de 2003 a 2017, em milhares de US\$ (FOB).

Fonte: BANCO CENTRAL DEL PARAGUAY, 2020.

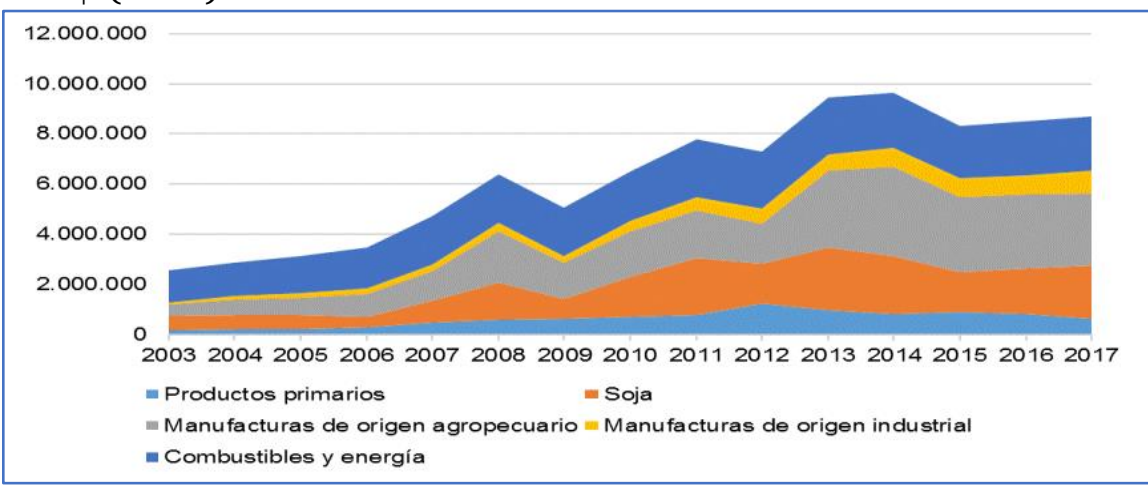

Os dados demonstram que a Lei de Maquila, em duas décadas de existência, atrelada a Política de Promoção à Exportação conseguiu resultados ainda muito pouco significantes para o cenário da economia total daquele país, apesar de ter um caráter crescente. Assim, os produtos base do Paraguai ainda permanecem fortes em sua atividade de exportação, que são os produtos primários, de modo que a Política de Promoção à Exportação dos bens do setor secundário ainda não foi capaz de mudar a base de exportação do Paraguai.

No entanto, vale verificar que, conforme o Gráfico 6, de 2003 a 2017, as exportações das manufaturas de origem industrial do Paraguai tiveram um 
crescimento em torno de $825,7 \%$, uma média de $55 \%$ ao ano, o que indica a possibilidade de, mantendo-se essa tendência num longo prazo, o setor industrial aumentar mais consideravelmente a sua participação nas exportações totais. Além disso, é importante ressaltar que dessas exportações as maquiladoras representavam 26\% em 2010 e 38\% em 2015, números bastante impactantes para o dinamismo do setor secundário do Paraguai.

Gráfico 6 - Exportações das manufaturas de origem industrial do Paraguai de 2003 a 2017, em Milhares de US\$ (FOB).

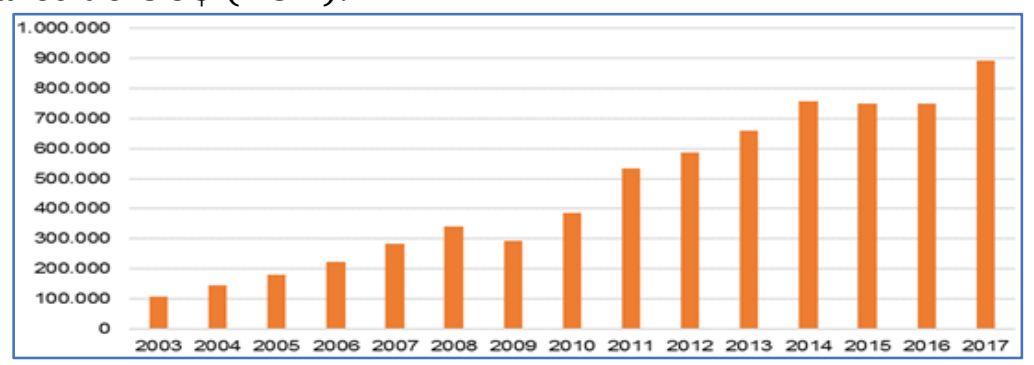

Fonte: BANCO CENTRAL DEL PARAGUAY, 2020.

Pode-se apontar aqui, outras consequências dessas atividades, como o de que a Indústria Maquiladora provocou economias externas ao dar visibilidade ao Paraguai nos últimos anos com os empresários dos países da região, se voltando para estudar o seu Programa de Maquila, pelos atrativos disponíveis ao investimento, resultando em curiosidade e empenho de acadêmicos até mesmo de outros países em compreender essa política. Como é o caso dessa pesquisa.

Há que se destacar ainda, a criação de postos de trabalho como um resultado, pois desde de 2001 acumularam-se 11554 postos de trabalho nas empresas maquiladoras, o que significa uma média de criação de 888 empregos por ano, e cerca de 96 pessoas trabalhando em cada empresa.

Novos parceiros comerciais, também podem ser considerados como um resultado, as maquiladoras proporcionaram uma maior integração regional com os países vizinhos, Brasil, Argentina e Uruguai, que mais investiram nas maquiladoras, mas também obteve relações com os Estados Unidos, que tem são proprietários das matrizes de seis maquiladoras, A China e a Itália que tem duas matrizes, cada uma, e outros que até o momento têm uma apenas, como Espanha, Hong Kong e Inglaterra. Fica evidenciado que alguns resultados foram positivos, mesmo que em pequena escala, apesar de não serem os resultados esperados.

\section{CONCLUSÃO}

Este artigo propôs-se a analisar o funcionamento e evolução do cenário das Maquiladoras do Paraguai e a testar se o IED na indústria maquiladora de exportação traria efeitos de crescimento das exportações de itens produzidos no setor secundário da economia paraguaia, processo que fundamenta a política de promoção à exportação do Paraguai. Além disso, aumentos na exportação e diversificação da base exportadora poderiam causar uma série de efeitos multiplicadores que no longo prazo e promoverem um desenvolvimento econômico e bem-estar social para a região.

Essa premissa auxiliou na formulação da metodologia que tentou testar os efeitos dessa estrutura operacional da Lei de Maquila para a economia do Paraguai. Assim, se aplicou a metodologia econométrica de séries temporais com modelo de Vetor Auto-Regressivo (VAR), confirmar se o IED provoca uma influência positiva sobre as exportações. Porém, a hipótese não pôde ser confirmada, demonstrando que 
o IED é irrelevante paras as variações das exportações. Mas, isso pode ser relacionado ao fato de a indústria paraguaia ainda ser pequena em volume, principalmente quando se compara com outros setores desta economia, principalmente o agropecuário.

Com esses resultados sugere-se que as operações executadas pela Lei de Maquila no Paraguai são pouco relevantes para as suas exportações, no período estudado. Isso não quer dizer que no longo prazo essa relação não pode se tornar mais relevante. Até porque, quando se observa individualmente o a evolução da indústria maquiladora de exportação, constata-se que ela teve uma evolução positiva e revela uma tendência de crescimento.

Também, é importante ressaltar a importância das maquiladoras para o setor secundário da economia paraguaia, o seu crescimento tem se mostrado cada vez mais representativo dentro da dinâmica de crescimento do setor secundário como um todo.

Por último, deve-se responder a pergunta-chave desse estudo: Quais os impactos da Lei de Maquila para o desenvolvimento econômico do Paraguai de 2003 a 2016?

Pode-se responder que os impactos da Lei de Maquila para o desenvolvimento do Paraguai ainda não são significativos para o país como um todo, porém eles se demonstram mais significativos para as localidades que recebem as indú strias quando se observa dentro do setor secundário, com maior representatividade de exportações, geração de empregos, renda e diversificação de atividades.

\section{REFERÊNCIAS}

BANCO CENTRAL DO PARAGUAI. Macrodatos. 2020. Disponível em: < https://www.bcp.gov.py/>. Acesso em: 20 Jan. 2020.

BORDA, Dionísio. Paraguay: resultados de las reformas (2003-2005) y sus perspectivas. Santiago, Chile: United Nations Publications, 2007. 64 p.

CEMAP - CAMARA DE EMPRESAS MAQUILADORA DEL PARAGUAY. Sobre Maquila. Disponível em: <http://www.maquila.org.py/?cat=5>. Acesso em: 25 Set. 2016.

COSTA, Francielly da Fonseca. Lei de Maquila: impactos no desenvolvimento econômico do Paraguai de 2003 a 2016. Dissertação (Mestrado em Desenvolvimento Regional e Agronegócio), Universidade Estadual do Paraná - UNIOESTE, Toledo. 2018.

DA SILVA JUNIOR, Julio Cesar Araujo; MENEZES, Gabrielito; FERNANDEZ, Rodrigo Nobre. Uma análise VAR das relações entre o mercado de ações e as variáveis macroeconômicas para o Brasil. Revista Economia e Desenvolvimento, Santa Maria, n. 23, p. 54-72, 2011.

ENDERS, Walter. Applied Econometric Time Series. John Wiley \& Son, Inc. USA, 1995. $485 \mathrm{p}$.

ESPOSITO NETO, Tomaz. As possibilidades e os limites do" realismo periférico": a política externa do Paraguai de 1954 a 1989. In: III ENCONTRO NACIONAL DA ASSOCIACÁO BRASILEIRA DE RELACÓES INTERNACIONAIS - ABRI 2011, 2011, 
São Paulo-SP, [online]. São Paulo: PUC Minas, 2011. Disponível em: < http://www.proceedings.scielo.br/scielo.php?pid=MSCoooooo0122011000300051\& script=sci_arttext\&tlng=pt >. Acesso em: 14 Mar. 2017.

FIEMS - FEDERAÇÃO DAS INDÚSTRIAS DO ESTADO DE MATO GROSSO DO SUL. Guia de Investimendo Paraguai. Mato Grosso do Sul, 2015. Disponível em: < http://www.fiems.com.br/public/confederacoes/guia_de_investimento_paraguai.pd f>. Acesso em: 21 Abr. 2017.

LEXICOON. Maquila [en línea] - Edição 3.9, Ene 2017. Disponível em: <http://lexicoon.org/es/maquila>. Acesso em: 23 Jun. 2017.

MACIEL, Ricardo Elias Antunes. A Maquila no Paraguai: modelo produtivo e integração no início do século XXI. Dissertação (Mestrado em Integração contemporânea da américa Latina) Universidade Federal da Integração LatinoAmericana - UNILA, Foz do Iguaçu. 2017.

MENDONÇA, Heloísa. Empresas brasileiras migram para o Paraguai atraídas por baixos custos. El País, São Paulo, 11 set. 2015. Disponível em: <http://brasil.elpais.com/brasil/2015/o9/10/politica/1441837292_242802.html>.

Acesso em: 15 Ago. 2016.

PARAGUAI. Congresso de la Nacion paraguaya. LEY No 1064 - De la Industria Maquiladora de Exportación. Assunção (DC), 1997. Disponível em: < https://www.aduana.gov.py/uploads/archivos/LEY\%20N_\%201064.pdf>. Acesso em: 25 Set. 2016.

PONTES, Lucélia Pontes e. Previsão de séries temporais: produção industrial e demanda de energia elétrica no Brasil. Tese (Doutorado em Economia), Universidade Católica de Brasília - UCB, Brasília. 2018.

SEBRAE - SERVIÇO BRASILEIRO DE APOIO ÀS MICRO E PEQUENAS EMPRESAS. Revista Soluções: A revista da pequena empresa no Paraná. vol. 01, $\mathrm{n}^{\mathrm{O}}$ 24, 2016. Disponível

em: <http://dl.dropboxusercontent.com/u/4978636/Revista\%20Soluções\%2oSEBRAE.p df $>$. Acesso em: 27 jul. 2019.

SILVEIRA, Cláudia Vera. Ensaios sobre a economia paraguaia: formação histórico econômica e dinâmica recente do emprego. Dissertação (Mestrado em Desenvolvimento Regional e Sistemas Produtivos). Universidade Estadual do Mato Grosso do Sul - UEMS, Ponta Porã. 2016.

TORRES, E.; BRAVO, R. El futuro de la maquila en el sector textil y confección. Revista Negocio Internacionales, n. 86, p. 11-13, 1999.

TURCO, Denise. O Paraguai custa menos. Revista Presença Internacional do Brasil. São Paulo, Ed. Totum Excelência Editorial, v. IX, n. 33. 2016. Disponível em: <https://issuu.com/revistapib/docs/pib33-simples>. Acesso em: o6 Mar. 2017.

VILLALPANDO Cadena, Paula. La evolución de la industria maquiladora en México. Revista Innovaciones de Negocios, México. 2004. Disponível em: < 
http://eprints.uanl.mx/12383/1/la\%2oevolucion\%2ode\%2ola\%2oindustria\%2omaq uiladora\%20en\%20mexico.pdf $>$. Acesso em: 20 jun. 2017.

WORLD BANK. World Development Indicators Database. GDP growth annual \% 2000-2015. 2015. Disponível em: <http://databank.worldbank.org/data/>. Acesso em: 28 set. 2016.

ZIVOT, Eric; WANG, Jiahui. Modeling financial time series with S-Plus®. $2^{\mathrm{a}}$ edição. New York: Springer Science \& Business Media, 2007. 998 p.

\section{Sobre o(s) Autor(es):}

\section{Francielly da Fonseca Costa}

Economista e Mestre em Desenvolvimento Regional e Agronegócio pela Universidade Estadual do Oeste do Paraná - Unioeste. Email: franciellypr@gmail.com

\section{Mirian Beatriz Braun}

Professora Associada do Colegiado de Ciências Econômicas e Professora e Pesquidora dos Programas de Pós-Graduação em Desenvolvimento Regional e Agronegócio e de Economia da UNIOESTE. Email: mirianbraun@unioeste.br

\section{Flávio Braga de Almeida Gabriel}

Professor Adjunto do Colegiado de Ciências Econômicas e Professor e pesquisador do Programa de Pós Graduação em Economia da UNIOESTE. Email: fbagabriel@gmail.com

\section{Gilson Batista de Oliveira}

Professor adjunto da Universidade Federal da Integração Latino-Americana (UNILA), Doutor em Desenvolvimento Econômico pela Universidade Federal do Paraná - UFPR/campus Curitiba. Email: profgilsonoliveira@gmail.com 